\title{
Fault tolerant control of a Proton Exchange Membrane Fuel Cell based on a Modified Failure Mode and Effect Analysis
}

\author{
Julie AUBRY \\ Symbio \\ Bavans, France \\ Univ. Bourgogne Franche-Comté \\ FEMTO-ST , FCLAB,CNRS \\ Belfort, France \\ julie.aubry@symbio.one \\ Noureddine Zerhouni \\ Univ. Bourgogne Franche-Comté \\ FEMTO-ST , FCLAB,CNRS \\ Besançon, France \\ noureddine.zerhouni@ens2m.fr
}

\author{
Nadia Yousfi Steiner \\ Univ. Bourgogne Franche-Comté \\ FEMTO-ST , FCLAB, CNRS \\ Belfort, France \\ nadia.steiner@femto-st.fr
}

\author{
Simon Morando \\ Symbio \\ Bavans, France \\ simon.morando@symbio.one
}

\begin{abstract}
Proton Exchange Membrane Fuel Cells (PEMFCs) are electrochemical energy converters, suitable for powering electric vehicles. However, for now, fuel cells fail to compete with traditional internal combustion engines (ICE). One of the reason is their limited durability and reliability compared to ICE which have a lifespan of around $8000 \mathrm{~h}$. One solution to improve fuel cell durability is to optimize the PEMFC operating conditions. This is possible by implementing an embedded fault tolerant control in the vehicle control system. In this context, this paper presents a Modified Failure Mode and Effect Analysis (MFMEA) for PEMFCs. An FMEA is an engineering tool that lists all failure modes a system can experience in a table. In this table, rankings define the criticality that the failure has for the system. In this article, a MFMEA is used as a fault tolerant control apparatus. For this, the MFMEA is coupled with a diagnosis tool. From the results provided by the diagnosis tool, the MFMEA evaluates the criticality of the failure by calculating a Risk Profile Number (RPN). Afterwards, corrective actions are proposed based on the RPN value.
\end{abstract}

Index Terms-PEMFC, FMEA, tolerant control, vehicle, faults, diagnostic

\section{INTRODUCTION}

Fuel cell systems are promising energy converters that emit lower greenhouse gases compare to conventional internal combustion engines and use fuel that can be produced by renewable sources. Proton Exchange Membrane Fuel Cells (PEMFC) are of first interest for vehicle application due to their high efficiency and low operating temperature, which enables a quick startup. However, before considering largescale industrialisation, their durability and reliability should be improved. The minimum lifetime target defined by the US Department of Energy is of 5000h for automotive applications [1]. To reach this target, numerous tools on fuel cells diagnosis

\author{
Daniel Hissel \\ Univ. Bourgogne Franche-Comté \\ FEMTO-ST , FCLAB, CNRS \\ Belfort, France \\ daniel.hissel@femto-st.fr
}

and prognosis have already been developed. These tools, when implanted online (in real time), propose adaptations to the fuel cell control system to correct failures and improve its lifetime [2]. FMEA (Failure Mode and Effect Analysis) is an industrial method, presented as a table, that lists all the failures a system can encounter and their criticality.

In this paper, a Modified FMEA (MFMEA) method is used to evaluate the criticality of one fault occurring in a PEMFC system. The obtained RPN (Risk Profile Number) is the decisive parameter to define the corrective actions that are taken to correct the failure. The method used is an active tolerant control process. This means that the controller is coupled with a diagnosis tool [3] as presented in Fig.1.The diagnosis block is an algorithm that detects if a fault is occurring. It returns the type of fault, its severity (S), its occurrence $(\mathrm{O})$ and the probability that this fault has been detected correctly (D). Those terms are explained in further detail in part IV . The diagnosis algorithm detects the fault based on signals (voltage) coming from the PEMFC system. The diagnostic methods are not presented because this is not the subject of this article. More information on this topic can

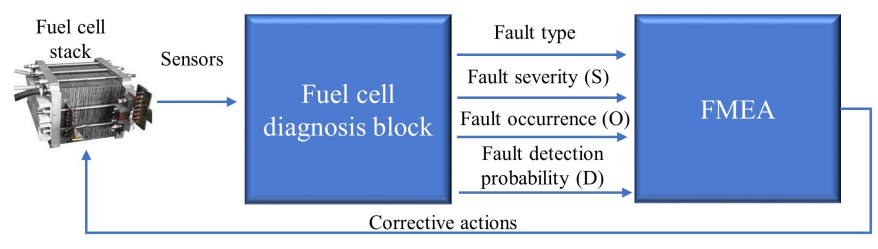

Fig. 1. Fault tolerant control process on fuel cell 
be found in reviews about existing PEMFCs fault diagnostic techniques [4], [5] and [6]. In this study, the diagnosis block is considered as perfect and reliable : it detects perfectly and identifies accurately a fault occurring.

This paper is organized as follows: the second section presents the FMEA method and its applications. The third part refers to the different occurring faults in a PEMFC and their mitigation strategies. The fourth part illustrates the developed MFMEA operation applied to a PEMFC system through an example. Finally, the fifth part is a conclusion together with a list of perspectives.

\section{FAILURE MODE AND EFFECT ANALYSIS}

Failure Mode and Effect Analysis (FMEA) is a tool that is used to identify the failures that can occur in a system. This tool is presented as a table, where failure modes are listed, as well as their severity, their consequences and their probability (or frequency) of occurrence. This method is widely used for industrial processes. Once failure modes have been identified, it is possible to schedule preventive actions related to the severity of the failure. Preventive actions enable to correct a failure without major impact on the system. Ahn et al. present a failure analysis of a propulsion system containing a gas turbine hybridized with a Molten Carbonate Fuel Cell [7]. They use fuzzy logic to compute the RPN. This interesting approach makes it possible to overcome and estimate uncertainties related to the subjectivity of the experience. The subjectivity issue in FMEA is analysed in further details in [8].

Witheley [9] developed a FMEA on PEMFC failure modes. In his thesis report, Witheley describes 27 failure modes and their respective effects on the system. He splits the failure modes into 4 categories: failures occurring at the membrane, the catalyst layers, the Gas Diffusion Layer (GDL) and the bipolar plates. The RPN is not calculated, yet a Petri-Net analysis has been carried out. This method is used to model degradation of a PEMFC.

In this paper, the FMEA is employed in a different way. Therefore, it is called a Modified FMEA (MFMEA). The basic concept of the FMEA is kept but the form is slightly different than typical functional FMEA. This is to adapt the tool to a tolerant control method. The Risk Profile Number is usually calculated using three factors (the occurrence, the detectability and the severity of the failure), but here, it is calculated with four parameters. The fourth parameter refers to the failure consequences.

To build an FMEA, failure modes must be identified. In the next part, the most common failure modes in a PEMFC are presented.

\section{FAILURE MODES IN PEMFCS AND THEIR MITIGATION STRATEGIES}

Failure modes, also called faults, are usual in PEMFC operation. The stack being the most expensive element regarding its lifetime, only this component is considered in this study (and not ancillaries failures). A second hypothesis concerns the type of failures that are taken into consideration. In a first objective, only completely or partly reversible faults are considered. Natural ageing phenomena requires a slightly different control, as it can be slowed but not stopped [2]. Thus, we will only focus on the fault tolerant control in this paper.

The faults that are studied are the most common ones in a PEMFC, namely flooding, drying, electrode poisoning, and fuel or air starvation. A brief description of those faults is provided to better understand the research axis of this study. Mitigation strategies, enabling to correct the fault, are also presented. Only on-board available solutions, without having an impact on driving, are studied.

\section{A. Flooding}

Water is a by-product of the electrochemical reaction occurring in a fuel cell and also comes from the humid inlet gases. When water condenses, it must be evacuated. Otherwise, water molecules block the arrival of reactants on active sites and prevent the electrochemical reaction from taking place [10], [11]. Water is evacuated through output gases that charge with water inside of the cell. The considered strategies to reduce flooding are the following:

- Decrease the relative humidity of inlet gases

- Increase air and/or hydrogen flow: water is evacuated through output gases. When the gases flow increases, more water is evacuated.

- Increase the stack temperature: this promotes water evaporation.

- Decrease gas inlet temperature: this decreases the absolute humidity of inlet gases. This is only possible in a closed cathode fuel cell system by varying cooling flow.

- Decrease the current: water production is increasing with current. Thus, if the current is lower, less water is produced.

\section{B. Drying}

The membrane of a fuel cell must be maintained hydrated to allow proton passage.Drying can cause significant mechanical damage to the membrane, for example micro cracks, which also promote crossover. This accelerates the degradation of the membrane even further. The strategies to mitigate drying are the following:

- Increase the relative humidity of inlet gases

- Decrease the air and/or hydrogen flow

- Decrease of the stack temperature: this promotes condensation

- Increase gas inlet temperature: this increases the absolute humidity of inlet gases

\section{Poisoning}

Some species can poison the PEMFC catalysts (mainly carbon monoxide $(\mathrm{CO})$ and sulfur hydroxide $\left(\mathrm{H}_{2} \mathrm{~S}\right)$. Catalysts adsorb contaminants which reduces the available surface left for hydrogen adsorption [12] and thus reduces the number of active sites available for the reactants. The two most common poisoning mitigation strategies are the following. 
Air bleeding, which enables the oxidation of the poisonous species, is possible at the cathode but requires a complicated control to maintain the safety during the operation at the anode [12]. Another solution is to put the fuel cell in a voltage range that prevents contaminants from being adsorbed by platinum and then increase hydrogen and air flow to remove the contaminants of the fuel stream.

- Increase air flow (air bleeding)

- Adjust the current and increase reactants flow: to be in a voltage range where the contaminant can be oxidized

\section{Starvation}

Sometimes, reactants do not reach active sites and the fuel cell lacks reactants compared to the power required by the load. This is a low stoichiometry factor phenomenon. Starvation phenomena, which is the particular case where the stoichiometry factor is less than 1 , is presented in further detail in [1]. The three existing mitigation methods are:

- Increasing air flow

- Increasing hydrogen flow

- Increasing pressure: this increases the reactive species volumetric concentration.

\section{E. Prioritization of the fault tolerant control}

Some mitigation techniques should be prioritized compared to others because they are more efficient or require less power from the ancillaries. The prioritization is presented on Fig.2.

The priority of the actions is chosen using three factors.

The first factor corresponds to the ease of on-board control. It is represented by the large arrow on Fig.2. There usually are no hydrogen flow controller. The flow is regulated by a pressure regulator which complicates the control. Accurate relative humidity and pressure regulators are very expensive. Therefore, automotive relative humidity and pressure regulators are generally not precise enough to be used for tolerant control.

The second factor is related to the system efficiency. For instance, the air flow is regulated by a compressor. When the air flow increases, the power consumed by the compressor increases. This lowers the fuel cell system efficiency.

The third factor is related to the current decrease. When the fuel cell current is low, its generated power may not be sufficient for the electric motor(s). The tolerant control strategy depends on the vehicle power architecture. If the fuel cell is hybridized with a low power (small battery) or low energy (supercapacitor) secondary energy source, it can be critical to lower the current. However, if this is not the case, deceasing the fuel cell current is a viable solution to correct a fault. Therefore, in this paper, decreasing the current is only considered if the fault is very critical.

\section{MFMEA APPLIED TO PEMFC}

\section{A. Presentation of the MFMEA}

This section presents a PEMFC fault tolerant control strategy based on a FMEA. Corrective actions are proposed based on the Risk Priority Number (RPN) provided by the
MFMEA. The RPN is calculated by multiplying the severity $(\mathrm{S})$, the occurrence $(\mathrm{O})$, the detection (D) and the failure's consequences severity $(\mathrm{C})$.

The severity $(\mathrm{S})$ corresponds to the negative impact that the failure has on the PEMFC.

The occurrence $(\mathrm{O})$ is defined considering the number of times this fault has been detected by the diagnosis algorithm during the last 10 minutes.

The probability of detecting the fault (D) is the probability for the diagnosis algorithm to detect this particular failure. For these 3 elements, a ranking (from 1 to 5 ) is proposed in the legend of Table.I.

C corresponds to the failure's consequences severity. The severity is determined with the same ranking than with $(\mathrm{S})$. The RPN is calculated as follows: $R P N=S \times O \times D \times \sum C$. It should be mentioned again that these coefficients are outputs of the diagnostic algorithm considered to be perfect and reliable in this study.

Corrective actions, presented in part III, can be applied by following the priority presented in Fig.2. In Table.I, one can notice that corrective actions are associated to a range of RPN.

\section{B. Illustrative example of the MFMEA}

To illustrate the method, Fig.3 presents an example applied to flooding. Three iterations of fault tolerant control are presented on Fig.3.

First, flooding is detected (Fig.2(a)) with RPN=36. On Table.I, one can see that the action associated to RPN $=36$ is to increase hydrogen flow and stack temperature. At the second iteration, flooding is detected once again with RPN $=54$. The corresponding action on Table.I is to increase hydrogen flow and stack temperature and decrease gas inlet temperature. At the third iteration, no fault is detected. The set-point for the operating parameters is the normal set-point, where there is no fault.

\section{Data sources}

This part aims to clarify the data sources used for this article. They can usually be separated into 3 main categories:

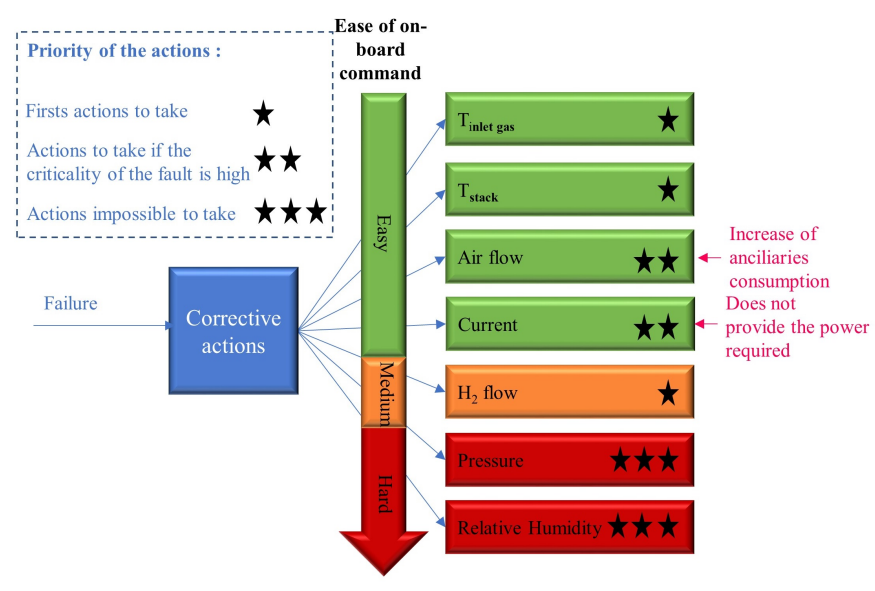

Fig. 2. Priority of control actions 
TABLE I

Modified Failure Mode and Effect Analysis (MFMEA) of a Proton Exchange Membrane Fuel Cell (PEMFC)

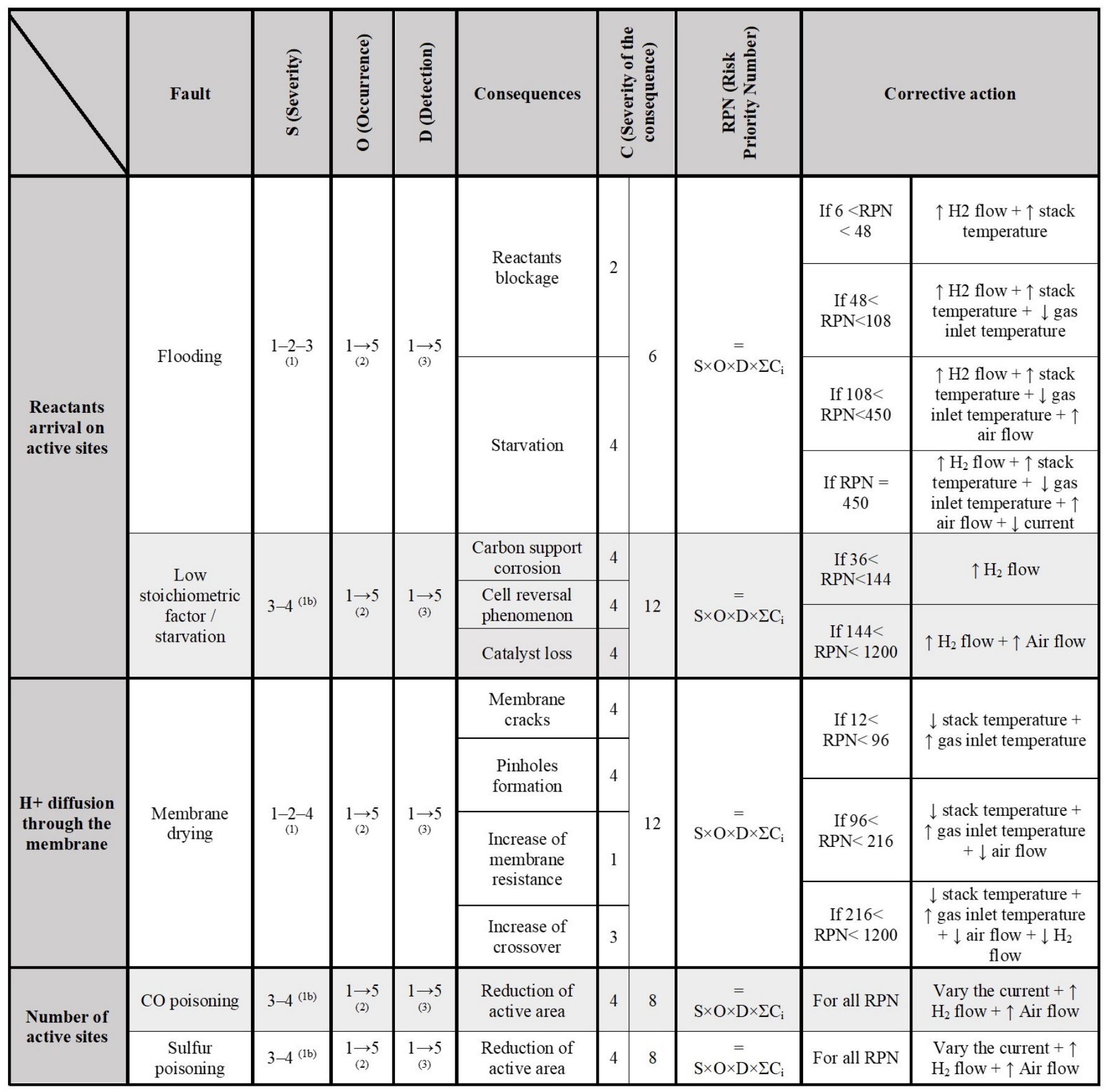

(1)/(1b) The severity varies whether the fault detection algorithm detects a light, medium or big fault ${ }^{(1)} /$ light or big fault (1b).

1: Impact reversible. Does not generate other faults

2: Impact reversible. May generate other faults

3: Impact only partially reversible. May generate other faults

4: Impact not reversible. May generate other faults

5: Immediate failure
(2) The occurrence corresponds to the number of times the fault occurred during the lasts 10 minutes
1: Occurrence $<1$
2: $1<$ Occurrence $<5$
3: $5<$ Occurrence $<10$
4: $10<$ Occurrence $<15$
5: Occurrence $>15$

(3) The detection is the number that corresponds to the probability of the algorithm to detect a fault

1: Detection probability $>95 \%$

2: $90 \%<$ Detection probability $<95 \%$

3: $80 \%<$ Detection probability $<90 \%$

4: $70 \%<$ Detection probability $<80 \%$

5: Detection probability $<70 \%$

RPN ranges for corrective actions

Flooding:

\section{6: RPN min}

48: $\mathrm{S}=\mathrm{O}=\mathrm{D}=2$

108: two of $\mathrm{S}, \mathrm{O}$ or $\mathrm{D}=3$ and the other $=2$

144: RPN max
Starvation

36: RPN min

144: two of $\mathrm{S}, \mathrm{O}$ or $\mathrm{D}=2$ and the other $=3$

1200: RPN max
Drying

12: RPN min

96: $\mathrm{S}=\mathrm{O}=\mathrm{D}=2$

216: two of $\mathrm{S}, \mathrm{O}$ or $\mathrm{D}=3$ and the other $=2$

1200: RPN max 


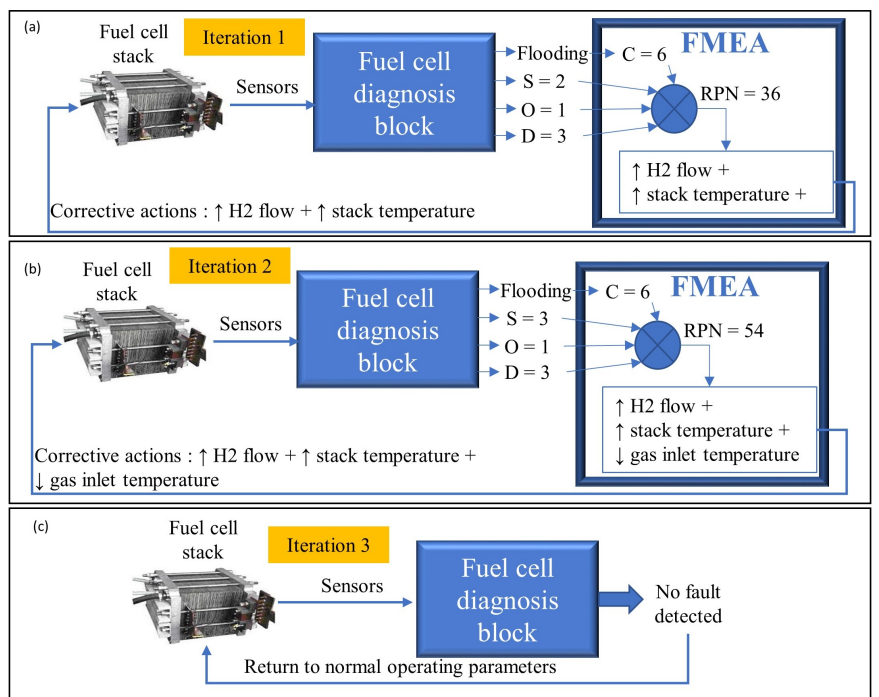

Fig. 3. Fault tolerant control based on FMEA: flooding example

experimental or simulation data (provided by fuel cell models) and knowledge coming from literature and expertise. In the framework of this paper, the expertise comes from the knowledge of the FEMTO-ST/FCLAB research laboratory and from the French fuel cell company Symbio. The data sources used in this paper are presented in Table.II. It is worth mentioning that the data coming from the expertise use coefficients, whose values are subjective. A validation has to be performed in the future to verify these parameters (combining other sources of expertise, validation tests...).

\section{CONCLUSION AND FUTURE WORK}

The main contribution of this article is the proposed MFMEA table, which facilitates the PEMFC tolerant control. An FMEA is a tool that lists failures modes in order to prevent it. In this paper, flooding, drying, poisoning and starvations issues on PEMFCs are investigated. Corrective actions are specified in the MFMEA table based on the RPN number. The MFMEA is coupled with a diagnostic algorithm considered as perfect and reliable. It is necessary to mention that the RPN and the associated corrective action are mostly based on subjective coefficients based on the expertise. Ideally, universal coefficient values should be defined by using multiple data sources. The uncertainties of those coefficients due to the different levels of expertise should also be determined.

TABLE II

DATA SOURCES

\begin{tabular}{|c|c|c|}
\hline Literature study & Expertise & $\begin{array}{l}\text { Experimental or } \\
\text { modelling }\end{array}$ \\
\hline $\begin{array}{l}\text { Understanding of fail- } \\
\text { ure modes in PEMFC, } \\
\text { their corrective ac- } \\
\text { tions and priority of } \\
\text { control }\end{array}$ & $\begin{array}{l}\text { - Ranking of S, O, D } \\
\text { and C } \\
\text { - RPN range for cor- } \\
\text { rective actions }\end{array}$ & $\begin{array}{l}\text { No experiment } \\
\text { or model for the } \\
\text { moment }\end{array}$ \\
\hline
\end{tabular}

Implementing type 2 fuzzy logic to define RPN ranges can also be investigated. Finally, it would be interesting to expand this analysis to other failure modes in PEMFC to obtain an exhaustive list of fault tolerant actions to take.

\section{REFERENCES}

[1] N. Yousfi-Steiner, P. Moçotéguy, D. Candusso, and D. Hissel, "A review on polymer electrolyte membrane fuel cell catalyst degradation and starvation issues: Causes, consequences and diagnostic for mitigation," Journal of Power Sources, vol. 194, pp. 130-145, Oct. 2009.

[2] R. Mezzi, Contrôle tolérant au vieillissement dans des systèmes pile à combustible PEMFC. PhD thesis, Univ. Bourgogne Franche Comté, 2019.

[3] J. Jiang and X. Yu, "Fault-tolerant control systems: A comparative study between active and passive approaches," Annual Reviews in Control, vol. 36, pp. 60-72, Apr. 2012.

[4] D. Hissel and M. Pera, "Diagnostic \& health management of fuel cell systems: Issues and solutions," Annual Reviews in Control, vol. 42, pp. 201-211, 2016.

[5] Z. Zheng, R. Petrone, M. Péra, D. Hissel, M. Becherif, C. Pianese, N. Yousfi Steiner, and M. Sorrentino, "A review on non-model based diagnosis methodologies for PEM fuel cell stacks and systems," International Journal of Hydrogen Energy, vol. 38, pp. 8914-8926, July 2013.

[6] R. Petrone, Z. Zheng, D. Hissel, M. Péra, C. Pianese, M. Sorrentino, M. Becherif, and N. Yousfi-Steiner, "A review on model-based diagnosis methodologies for PEMFCs," International Journal of Hydrogen Energy, vol. 38, pp. 7077-7091, June 2013.

[7] J. Ahn, Y. Noh, S. H. Park, B. I. Choi, and D. Chang, "Fuzzy-based failure mode and effect analysis (FMEA) of a hybrid molten carbonate fuel cell (MCFC) and gas turbine system for marine propulsion," Journal of Power Sources, vol. 364, pp. 226-233, Oct. 2017.

[8] C. Spreafico, D. Russo, and C. Rizzi, "A state-of-the-art review of FMEA/FMECA including patents," Computer Science Review, vol. 25, pp. 19-28, Aug. 2017.

[9] M. Whiteley, Advanced Reliability Analysis of Polymer Electrolyte Membrane Fuel Cells In Automotive Applications. $\mathrm{PhD}$ thesis, Loughborough University, 2016.

[10] J. O'Rourke, M. Ramani, and M. Arcak, "In situ detection of anode flooding of a PEM fuel cell," International Journal of Hydrogen Energy, vol. 34, pp. 6765-6770, Aug. 2009.

[11] N. Yousfi-Steiner, P. Moçotéguy, D. Candusso, D. Hissel, A. Hernandez, and A. Aslanides, "A review on PEM voltage degradation associated with water management: Impacts, influent factors and characterization," Journal of Power Sources, vol. 183, pp. 260-274, Aug. 2008.

[12] N. Zamel and X. Li, "Effect of contaminants on polymer electrolyte membrane fuel cells," Progress in Energy and Combustion Science, vol. 37, pp. 292-329, June 2011. 